\title{
Article \\ One Year Assessment of the Hearing Preservation Potential of the EVO Electrode Array
}

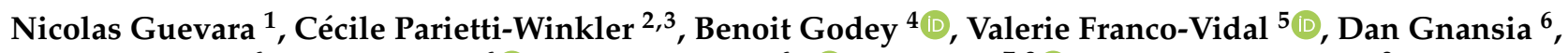 \\ Marine Ardoint ${ }^{6}$, Michel Hoen ${ }^{6}\left(\mathbb{D}\right.$, Chadlia Karoui ${ }^{6, *}{ }^{\infty}$, Eric Truy ${ }^{7,8} \mathbb{D}^{\circ}$, Christophe Vincent ${ }^{9}$, Isabelle Mosnier ${ }^{10}$ \\ and Yann Nguyen ${ }^{10,11}$
}

Citation: Guevara, N.;

Parietti-Winkler, C.; Godey, B.; Franco-Vidal, V.; Gnansia, D.; Ardoint, M.; Hoen, M.; Karoui, C.; Truy, E.; Vincent, C.; et al. One Year Assessment of the Hearing Preservation Potential of the EVO Electrode Array. J. Clin. Med. 2021, 10, 5604. https://doi.org/10.3390/ jcm10235604

Academic Editors:

Giuseppe Magliulo and Ja-Won Koo

Received: 12 October 2021

Accepted: 25 November 2021

Published: 29 November 2021

Publisher's Note: MDPI stays neutral with regard to jurisdictional claims in published maps and institutional affiliations.

Copyright: (C) 2021 by the authors. Licensee MDPI, Basel, Switzerland. This article is an open access article distributed under the terms and conditions of the Creative Commons Attribution (CC BY) license (https:/ / creativecommons.org/licenses/by/ $4.0 /)$.
1 Institut Universitaire de la Face et du Cou (University Institute of the Face and Neck), Centre Hospitalier Universitaire de Nice, Université Côte d'Azur, 06000 Nice, France; guevara.n@chu-nice.fr

2 Service d'ORL et CCF, CHU Nancy, 54000 Nancy, France; c.parietti@chru-nancy.fr

3 Laboratoire Développement, Adaptation et Handicap (DevAH-EA 3450), Faculty of Medicine and Faculty of Sciences and Sport, University of Lorraine, Vandoeuvre-lès-Nancy, 54000 Nancy, France

4 Department of Otolaryngology, Head Neck Surgery, University Hospital Ponchaillou, 35000 Rennes, France; benoit.godey@chu-rennes.fr

5 Ear, Nose, and Throat Department, Bordeaux University Hospital, 33000 Bordeaux, France; valerie.vidal@chu-bordeaux.fr

6 Research \& Technology, Oticon Medical, Technologies and Gene Therapy for Deafness, Hearing Institute, Institut Pasteur/Inserm, 16096 Paris, France; dagn@oticonmedical.com (D.G.); mard@oticonmedical.com (M.A.); mhoe@oticonmedical.com (M.H.)

7 Service d'ORL, De Chirurgie Cervico-Faciale et D'audiophonologie, Hôpital Edouard Herriot, Hospices Civils de Lyon, Université de Lyon, 69000 Lyon, France; eric.truy@chu-lyon.fr

8 Centre de Recherches en Neurosciences de Lyon, Équipe IMPACT, INSERM UMRS1028 CNRS UMR5292, 69000 Lyon, France

9 Otology and Oto-Neurology Department, Lille University Hospital, 59000 Lille, France; christophe.vincent@chru-lille.fr

10 ENT Department, Pitié Salpêtrière Hospital, APHP/Sorbonne Université, 75013 Paris, France; isabelle.mosnier@aphp.fr (I.M.); yann.nguyen@inserm.fr (Y.N.)

11 Institut de L'audition Pasteur/Inserm UMR 1120, 75012 Paris, France

* Correspondence: chok@oticonmedical.com

\begin{abstract}
Background: A prospective longitudinal multicentre study was conducted to assess the oneyear postsurgical hearing preservation profile of the $\mathrm{EVO}^{\mathrm{TM}}$ electrode array. Methods: Fifteen adults presenting indications of electro-acoustic stimulation (pure-tone audiometry (PTA) thresholds $\leq 70 \mathrm{~dB}$ below $750 \mathrm{~Hz}$ ) were implanted with the $\mathrm{EVO}^{\mathrm{TM}}$ electrode array. Hearing thresholds were collected at five time-points from CI activation to twelve months (12M) after activation. Hearing thresholds and hearing preservation profiles (HEARRING group classification) were assessed. Results: All subjects had measurable hearing thresholds at follow-up. No case of complete loss of hearing or minimal hearing preservation was reported at any time point. At activation $\left(\mathrm{N}_{\mathrm{act}}=15\right)$, five participants had complete hearing preservation, and ten participants had partial hearing preservation. At the $12 \mathrm{M}$ time point $\left(\mathrm{N}_{12 \mathrm{~m}}=6\right)$, three participants had complete hearing preservation, and three participants had partial hearing preservation. Mean hearing loss at activation was $11 \mathrm{~dB}$ for full range PTA and $25 \mathrm{~dB}$ for PTAs low-frequency $(125-500 \mathrm{~Hz})$. Conclusions: This study provides the first longitudinal follow-up on associated hearing profiles to the $\mathrm{EVO}^{\mathrm{TM}}$ electrode array, which are comparable to the literature. However, other studies on larger populations should be performed.
\end{abstract}

Keywords: cochlear implantation; hearing preservation; HEARRING classification; functional hearing; EVO electrode array

\section{Introduction}

The cochlear implant (CI) can constitute a dilemma for subjects with severe highfrequency hearing loss (HL). On the one hand, this population mostly does not benefit 
from conventional hearing aids. On the other hand, a traumatic CI insertion could damage their low-frequency residual hearing. Preservation of the cochlear structure is key to the success of cochlear implantation for this population. When these subjects are CI candidates (averaged hearing thresholds $<80 \mathrm{~dB}$ HL according to recommendations of CI manufacturers), they may be offered electro-acoustic stimulation (EAS). However, EAS is only possible if the candidate has sufficient functional residual hearing after surgery. With the increasing understanding of the mechanisms underlying intracochlear trauma and the establishment of predictive factors associated with low-frequency hearing preservation (HP), recent decades have witnessed an evolution towards atraumatic surgery [1,2], accompanied by an evolution of CI components [3]. Atraumatic surgery has been shown to improve HP scores [4,5]. Implant manufacturers have improved their electrode arrays by making them thinner and more flexible [6], aiming for trauma-free insertion so that the cochlear structures can be preserved. The length of the electrode array is also a key variable. For example, Gantz et al. [7] worked on a short $10 \mathrm{~mm}$ array, the aim being not to damage the apical, low-frequency encoding cells. They were able to preserve residual hearing partially or completely in $96 \%$ of cases. Residual hearing can last years after implantation [8,9], even in elderly patients [10], but it is also often lost; in the latter case, electrical stimulation from the CI would be the only route to provide hearing, and a $10 \mathrm{~mm}$ array would not be as efficient as a standard-length array, because of its reduced cochlear coverage. A reimplantation would then be more appropriate [11]. It is therefore recommended to insert over at least $360^{\circ}$, which corresponds to 18-24 $\mathrm{mm}$ (variable depending on the anatomy of the cochlea) of insertion, for a frequency region close to $1 \mathrm{kHz}[12,13]$. This appears to be a good compromise to preserve residual hearing and obtain performance with the $\mathrm{CI}$ alone if residual hearing post-implantation is lost [14].

The $\mathrm{EVO}^{\mathrm{TM}}$ electrode array has been designed to preserve hearing. This $24 \mathrm{~mm}$ long electrode array carries 20 electrodes. Its narrow diameter and flexibility, as well as its soft surface and round tip, were designed for lower-trauma insertion [15]. Extra-cochlear rings have been placed to facilitate insertion and decrease insertion force. A previous study with the $\mathrm{EVO}^{\mathrm{TM}}$ electrode array showed that the insertion forces used during implantation were considerably reduced-over 32\% compared to the standard electrode array [16]. Bento et al. [17] evaluated the combination of a soft-surgery procedure implicating roundwindow insertion, the use of dexamethasone and hyaluronic acid during surgery, with the use of the EVOTM electrode array on hearing preservation in seven participants with low-frequency functional hearing. Their preliminary outcomes described hearing threshold shifts after activation of $24.5 \pm 18.2 \mathrm{~dB}$ HL up to $500 \mathrm{~Hz}$ and $21.8 \pm 19.2 \mathrm{~dB}$ up to $1 \mathrm{kHz}$. To date, no longitudinal study has investigated the atraumatic and HP profile of $\mathrm{CI}$ users with the $\mathrm{EVO}^{\mathrm{TM}}$ electrode array only.

The purpose of the present study was to evaluate the atraumatic nature of the $\mathrm{EVO}^{\mathrm{TM}}$ electrode array with the assessment of HP and functional hearing profiles up to twelve months after CI activation.

\section{Materials and Methods}

This prospective multicentric clinical investigation was carried out in accordance with the regulations in force based on the provisions stipulated in the Declaration of Helsinki and was registered in the U.S. National Library of Medicine ClinicalTrials.gov database (identifier NCT02966379). For this purpose, the favourable opinion of the CPP was required and obtained (RCB:2015-A00445-44), as well as the authorization of the French health authorities (ANSM). Clinical research was carried out in accordance with good clinical practices (ICH standard) and NF ISO 14155:2011 and in accordance with the MR001 reference methodology of the French National Information Science and Liberties Commission (CNIL). Participants were included in seven French CI centres (Lille, Bordeaux, Paris Pitié Salpêtrière, Nice, Nancy, Lyon, Rennes). The investigation occurred between April 2016 and April 2019. 


\subsection{Participant Selection}

To be included, CI candidates had to be adults ( $\geq 18$ years old) with post-lingual deafness onset, be fluent in French and follow the standard post-implantation follow-up and rehabilitation program. All procedures were primary cochlear implantations. Tonal audiometry had to be showing functional auditory residual hearing in low frequencies (pure-tone audiometry (PTA) thresholds $\leq 70 \mathrm{~dB}$ up to $500 \mathrm{~Hz}$ included) prior to implantation. Tonal threshold at non-aided condition had to be measurable on at least one frequency before activation of the implant. Written informed consent was obtained from each patient to participate in the study and to receive the Digisonic ${ }^{\circledR}$ SP cochlear implant, including the EVO $^{\mathrm{TM}}$ electrode array and an electro-acoustic prototype sound processor (EAS)-(Oticon Medical, Vallauris, France). Fifteen adult CI candidates were initially included in the study. All their demographics are summarized in Table 1.

Table 1. Demographic characterization of all included participants. $(n=15)$.

\begin{tabular}{|c|c|c|c|c|c|c|c|}
\hline \multirow{2}{*}{ ID. } & \multirow{2}{*}{ Age } & \multirow{2}{*}{ Gender } & \multicolumn{2}{|c|}{ Age at Deafness Onset (Years) } & \multirow{2}{*}{ Etiology } & \multicolumn{2}{|c|}{ HL Evolution Severe/Profound } \\
\hline & & & $\mathbf{R}$ & L & & $\mathbf{R}$ & L \\
\hline 1 & 76 & M & 66 & 1 & Presbyacousis & progressive & progressive \\
\hline 2 & 55 & $\mathrm{~F}$ & 37 & 37 & Genetic & sudden & sudden \\
\hline 3 & 53 & M & 1 & 1 & Unknown & progressive & progressive \\
\hline 4 & 78 & $\mathrm{~F}$ & 61 & 66 & Unknown & n.a & n.a \\
\hline 5 & 39 & $\mathrm{~F}$ & 4 & 4 & Meningitis & progressive & progressive \\
\hline 6 & 69 & $\mathrm{~F}$ & 42 & 42 & Unknown & progressive & progressive \\
\hline 7 & 34 & M & 5 & 5 & Unknown & sudden & progressive \\
\hline 8 & 71 & $\mathrm{~F}$ & 30 & 1 & Unknown & progressive & sudden \\
\hline 9 & 86 & F & 47 & 47 & Unknown & sudden & sudden \\
\hline 10 & 36 & $\mathrm{~F}$ & n.a & n.a & n.a & n.a & n.a \\
\hline 11 & 61 & M & 34 & 34 & Unknown & progressive & progressive \\
\hline 12 & 46 & $\mathrm{~F}$ & 1 & 1 & Ototoxic & progressive & progressive \\
\hline 13 & 57 & M & 45 & 45 & Genetic & sudden & sudden \\
\hline 14 & 81 & M & 69 & 69 & Unknown & progressive & progressive \\
\hline 15 & 72 & $\mathrm{~F}$ & 53 & 53 & Unknown & progressive & progressive \\
\hline
\end{tabular}

M: Male; F: Female; R:Right; L:Left; HL: Hearing loss.

The study included eight time points: two preliminary visits, the surgery and five follow-up visits. The two pre-operative visits consisted of the inclusion visit and the auditory preoperative assessment visit in a two-month period prior to the CI surgery. Unaided auditory hearing levels were measured using free-field warble tone thresholds at 125, 250, 500, 750, 1000, 2000 and $4000 \mathrm{~Hz}$. The EAS activation occurred one month after cochlear implantation. At time points after activation, if at least one hearing threshold was detectable, all hearing thresholds were measured. If not, the participant was equipped with a Saphyr ${ }^{\circledR}$ sound processor providing electric-only stimulation (ES)—(Oticon Medical, Vallauris, France) and exited from the protocol. This was repeated at one (1M), three (3M), six (6M) and twelve months (12M) after activation. At $6 \mathrm{M}$ and12M time points, participants were also given the choice to keep the EAS or not.

\subsection{Surgical Procedure}

To assess the success of atraumaticity of the EVOTM electrode array, a standard CI surgery procedure based on round window insertion was preferred. Recommendations were that the surgeon accesses the cochlea by posterior tympanotomy, locates the round window and goes through to insert the electrode array. The implant body had to be fixed before opening the round window. The opening time of the round window had to be less than $2 \mathrm{~min}$. The surgeon inserted the electrode array into the tympanic ramp following the cochlear spiral and finalized the insertion by resting on the push rings of the array. In case of difficult insertion, the surgeon was advised to stop at the first point of resistance. Corticosteroids were systematically administered to the participants $(1 \mathrm{mg} / \mathrm{kg}$ solumedrol). 


\subsection{Outcomes}

The first outcome measure was the change in hearing thresholds at 125, 250, 500, 750, 1000, 2000 and $4000 \mathrm{~Hz}$, assessed between pre- and post-implantation at activation and 1M, $3 \mathrm{M}, 6 \mathrm{M}$ and $12 \mathrm{M}$ time points. The second outcome measure consisted of the assessment of residual $\mathrm{HP}$ after implantation of the $\mathrm{EVO}^{\mathrm{TM}}$ electrode array. The HEARRING Group approach ([18]—https:/ / www.hearring.com/ accessed on 12 October 2021) was used to classify the different HP profiles in the study population (Table S1). The HEARRING formula expresses post-operative thresholds as a percentage of pre-operative threshold and corrects by the upper limit of measurable thresholds as described in Formula (1):

$$
\mathrm{HP}=[1-(((\text { PTApost }- \text { PTApre })) /((\text { PTAmax }- \text { PTApre }))) \times 100](\%)
$$

where PTA post is the pure tone average threshold measured postoperatively, PTA pre is pure tone average measured pre-operatively, PTA max is the compliance limits of the audiometer and HP is the hearing preservation numerical scale in percent [18]. The maximal hearing level of the audiometer was the same as that defined by the HEARRING group for each frequency: $125 \mathrm{~Hz}(90 \mathrm{~dB}), 250 \mathrm{~Hz}(105 \mathrm{~dB}), 500 \mathrm{~Hz}(110 \mathrm{~dB})$ and $750 \mathrm{~Hz}$ (115 dB). Depending on the HP scale, the HP could be complete (if $>75 \%$ ), partial (if ranging between 25 and $75 \%$ ) or minimal (if $<25 \%$ ), as suggested by The HEARRING classification. If no measurable hearing is possible, it is classified as complete loss of hearing. To assess the change in hearing threshold over the different time points after activation, mean hearing loss (HL) as PTA difference between one time point and a preceding time point was calculated both at full range audiometry $(125-4000 \mathrm{~Hz})$ and in the low frequency region $(125-500 \mathrm{~Hz})$. Functional hearing at low-frequency regions was also investigated and defined as low-frequency PTA $(0.125-0.5 \mathrm{kHz}) \leq 80 \mathrm{~dB}(\mathrm{HL})$, as in recent studies $[19,20]$. To further explore the data regarding subjects with functional hearing, low-frequency HP was also assessed using the standard classification $[9,21]$, defined as complete preservation if mean hearing threshold shift $\leq 10 \mathrm{~dB}$; partial preservation for a mean shift between $10 \mathrm{~dB}$ and $30 \mathrm{~dB}$; and minimal preservation if shift $\geq 30 \mathrm{~dB}$. Loss of residual hearing would be defined when no measurable threshold is possible at maximum hearing levels.

\subsection{Statistical Analyses}

All quantitative data were presented as mean, standard deviation and median. Analyses were conducted using RStudio Team (RStudio Inc., Boston, MA, USA). For each analysis on hearing threshold follow-up, a linear mixed-effect (LME) model for repeated measures was fitted to the data with a random intercept for participants and a fixed effect for frequency and month as covariates. To further explore the collected data, a repeated-measures ANOVA and post hoc pairwise comparisons were conducted. Statistical significance was defined as $p \leq 0.05$. Some demographic data were missing when performing the analysis (i.e., n.a. in Table 1). These data were not included in any analysis. Correlation analysis was performed using a Pearson test.

\section{Results}

Fifteen CI users (mean age $=60.7 \pm 17$ years, range (31:86), 6 males and 9 females) underwent $\mathrm{CI}$ surgery with a unilateral $\mathrm{EVO}^{\mathrm{TM}}$ electrode array, using the $\mathrm{HP}$ surgical procedure (5 right-sided CIs, 10 left-sided CIs). Full insertion of the electrode array was achieved in $53.3 \%$ of the cases, in agreement with the instruction given to surgeons to stop insertion at first resistance to prioritize atraumaticity of the insertion over full insertion. Mean number of inserted electrodes was $18.8 \pm 1.4$, range (17:20). At activation time point, mean number of activated electrodes was $18.5 \pm 1.6$, range (16:20). Hearing thresholds were collected for all participants up to $3 \mathrm{M}$ but for one participant who decided to step-out of the study for personal reasons (non-adherence to protocol constraints) (i.e., sample size at activation time point: $\mathrm{N}_{\mathrm{act}}=15$, sample size at the $1 \mathrm{M}$ time point: $\mathrm{N}_{1 \mathrm{~m}}=15$, sample size at the 3M time point: $\mathrm{N}_{3 \mathrm{~m}}=14$ ). At the $6 \mathrm{M}$ time point, as participants were given the 
choice of changing the sound processor, and one participant decided to be fitted with the $\mathrm{ES}$ and thus left the study (i.e., sample size at the $6 \mathrm{M}$ time point $\mathrm{N}_{6 \mathrm{~m}}=13$ ). At the $12 \mathrm{M}$ time point, six participants chose to remain with the EAS (i.e., sample size at the $12 \mathrm{M}$ time point: $\mathrm{N}_{12 \mathrm{mact}}=6$ ), while seven participants quit the study due to personal constraints or preference for an ES trial. All collected individual PTAs are presented in Table 2. HP score percentages and classification according to the HEARRING group along with follow-up time points are available in Supplemental Material 1 both for the full range PTAs and PTAs of low-frequency $(0.125-500 \mathrm{~Hz})$.

Table 2. Individual PTAs for all included participants. $(n=15)$. Pre-op $=$ pre-operative visit. Act $=$ activation day visit. $1 \mathrm{M}$, $3 \mathrm{M}, 6 \mathrm{M}$ and $12 \mathrm{M}$ refer, respectively, to one-month, three-month, six-month and twelve-month visits after activation. $\mathrm{x}$ refers to participants out of study. PTA = pure-tone audiometry; $\mathrm{HL}=$ hearing loss.

\begin{tabular}{|c|c|c|c|c|c|c|c|c|c|c|c|c|c|}
\hline \multirow{2}{*}{ ID } & \multirow{2}{*}{ CI Ear } & \multicolumn{6}{|c|}{ Low-Frequency PTA [125-500 Hz] } & \multicolumn{6}{|c|}{ Full Range PTA (dB HL) [125-4000 Hz] } \\
\hline & & Pre-op & Act & $1 \mathbf{M}$ & $3 \mathbf{M}$ & $6 \mathrm{M}$ & $12 \mathrm{M}$ & Pre-op & Act & $1 \mathbf{M}$ & $3 \mathbf{M}$ & $6 \mathrm{M}$ & $12 \mathrm{M}$ \\
\hline 1 & right & 56,7 & 66.7 & 68.3 & 70.0 & 85.0 & $\mathrm{x}$ & 77.7 & 83 & 83.4 & 88.6 & 90.5 & $\mathrm{x}$ \\
\hline 2 & left & 46.7 & 45.0 & 65.0 & 53.3 & 73.3 & 85.0 & 78.2 & 79.1 & 85 & 88 & 93.4 & 96.6 \\
\hline 3 & left & 43.3 & 76.7 & 78.3 & 63.3 & 60.0 & $x$ & 81.1 & 90.9 & 93.6 & 88.4 & 85.9 & $x$ \\
\hline 4 & left & 48.3 & 80.0 & 61.7 & 70.0 & 63.3 & 63.3 & 79.1 & 93 & 88.9 & 84.5 & 86.8 & 85.9 \\
\hline 5 & left & 60.0 & 58.3 & 48.3 & 43.3 & 46.7 & 51.7 & 89.8 & 89.2 & 84.8 & 85.2 & 86.1 & 87.5 \\
\hline 6 & left & 15.0 & 66.7 & 75.0 & 80.0 & 73.3 & $x$ & 63 & 80.2 & 81.1 & 93.9 & 83.2 & $x$ \\
\hline 7 & right & 30.0 & 38.3 & 48.3 & 46.7 & 36.7 & 40.0 & 81.6 & 83.9 & 84.8 & 84.3 & 82 & 82.5 \\
\hline 8 & right & 63.3 & 85.0 & 85.0 & 88.3 & $x$ & $x$ & 60.2 & 83.6 & 84.5 & 85.7 & $x$ & $x$ \\
\hline 9 & left & 55.0 & 86.7 & 83.3 & $\mathrm{x}$ & $x$ & $x$ & 88.4 & 97 & 96.1 & $\mathrm{x}$ & $x$ & $x$ \\
\hline 10 & left & 31.7 & 61.7 & 70.0 & 68.3 & 55.0 & 51.7 & 74.5 & 89.8 & 92 & 91.6 & 88.4 & 84.1 \\
\hline 11 & right & 21.7 & 38.3 & 23.3 & 28.3 & 25.0 & $x$ & 65.9 & 71.4 & 68.6 & 66.8 & 66.6 & $x$ \\
\hline 12 & right & 20.0 & 53.3 & 56.7 & 55.0 & 65.0 & 56.7 & 71.6 & 83.9 & 83 & 86.6 & 86.8 & 88.9 \\
\hline 13 & left & 41.7 & 96.7 & 95.0 & 101.7 & 101.7 & $x$ & 75.2 & 99.8 & 99.3 & 101.1 & 100.7 & $x$ \\
\hline 14 & left & 60.0 & 83.3 & 88.3 & 91.7 & 91.7 & $x$ & 69.5 & 88 & 90.5 & 91.6 & 97.5 & $x$ \\
\hline 15 & left & 30.0 & 65.0 & 63.3 & 75.0 & 68.3 & $x$ & 70.7 & 88.2 & 88.4 & 93.9 & 92 & $x$ \\
\hline
\end{tabular}

\subsection{Early Follow-Up Data}

At activation $\left(\mathrm{N}_{\mathrm{act}}=15\right)$, all participants had measurable hearing thresholds, as described in Figure 1. Linear mixed-effect analysis revealed that changes in hearing thresholds between time points were not all similar, with at least one change in the three time points as statistically significantly different from others $(\mathrm{F}(3,371)=34.8, p<0.001)$ and were as well not all similar with at least one change at one of the five test-frequencies as statistically significantly different from the others $(\mathrm{F}(6,370)=194.4, p<0.001)$ with a significant interaction effect between frequency and time point $(\mathrm{F}(18,371)=2.4, p=0.001)$. Post hoc pairwise multi-comparisons indicated that changes at activation, at $1 \mathrm{M}$ and at $3 \mathrm{M}$, were significantly higher from hearing thresholds measured at the preoperative visit between $125 \mathrm{~Hz}$ and $1000 \mathrm{~Hz}$. No significant differences were found at both $2000 \mathrm{~Hz}$ and $4000 \mathrm{~Hz}$ during follow-up. No significant difference was found between post-operative hearing thresholds across subjects.

Over the early follow-up period, no participant showed a total loss of hearing or a minimal HP according the HEARRING classification. At activation $\left(\mathrm{N}_{\text {act }}=15\right)$, five participants $(33.3 \%)$ had complete HP (range $=(84: 102) \%)$, and ten participants $(66.7 \%)$ had partial HP (range $=[29: 68] \%)$. Similarly, at the $1 \mathrm{M}$ time point $\left(\mathrm{N}_{1 \mathrm{~m}}=15\right)$, five participants $(33.3 \%)$ had complete HP (range $=(79: 125) \%)$, and ten participants $(66.7 \%)$ had partial HP (range $=(31: 70) \%)$. At the $3 \mathrm{M}$ time point $\left(\mathrm{N}_{3 \mathrm{~m}}=14\right)$, five participants $(35.7 \%)$ had complete $\mathrm{HP}($ range $=(75: 118) \%)$, and nine participants $(64.3 \%)$ had partial HP $($ range $=(84: 02) \%)$. 


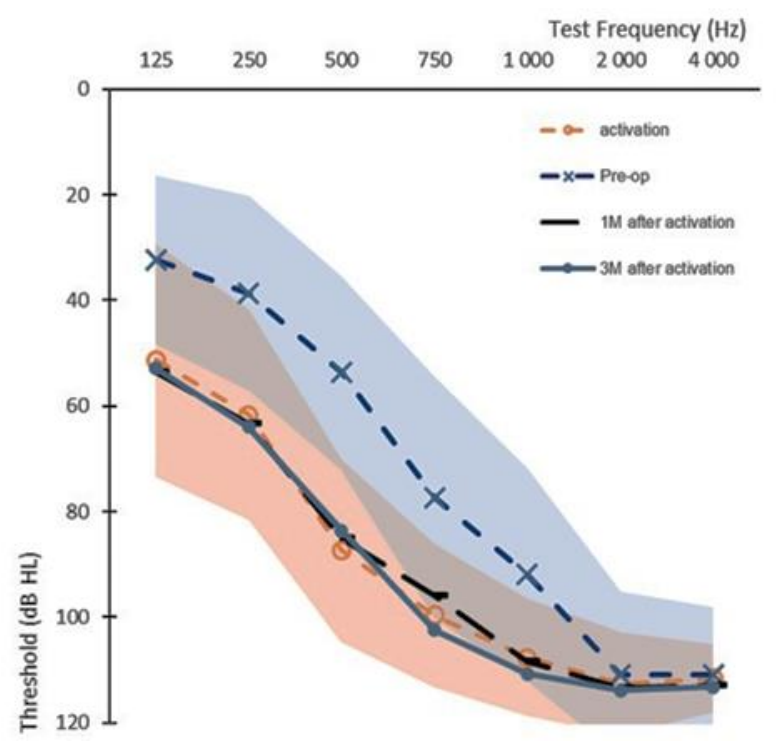

\begin{tabular}{|c|c|c|c|c|c|c|c|}
\hline \multicolumn{8}{|c|}{ Test Frequency $(\mathrm{Hz})$} \\
\hline & 125 & 250 & 500 & 750 & 1000 & 2000 & 4000 \\
\hline \multicolumn{8}{|c|}{ Pre-op thresholds (dB HL) } \\
\hline average & 32 & 39 & 54 & 77 & 92 & 111 & 111 \\
\hline S.D. & 16 & 19 & 18 & 23 & 20 & 16 & 13 \\
\hline median & 35 & 40 & 55 & 70 & 95 & 120 & 115 \\
\hline \multicolumn{8}{|c|}{ Activation day thresholds (dB HL) } \\
\hline average & 51 & 62 & 87 & 100 & 108 & 113 & 112 \\
\hline S.D. & 22 & 20 & 17 & 14 & 11 & 10 & 6 \\
\hline median & 45 & 60 & 90 & 100 & 110 & 120 & 115 \\
\hline \multicolumn{8}{|c|}{$1 \mathrm{M}$ after activation thresholds (dB HL) } \\
\hline average & 54 & 63 & 85 & 96 & 108 & 113 & 113 \\
\hline S.D. & 21 & 20 & 21 & 15 & 12 & 11 & 6 \\
\hline median & 55 & 60 & 90 & 95 & 110 & 120 & 115 \\
\hline \multicolumn{8}{|c|}{$3 \mathrm{M}$ after activation thresholds ( $\mathrm{dB} \mathrm{HL}$ ) } \\
\hline average & 53 & 64 & 84 & 103 & 111 & 114 & 113 \\
\hline S.D. & 22 & 24 & 19 & 15 & 15 & 9 & 5 \\
\hline median & 50 & 63 & 90 & 105 & 120 & 120 & 115 \\
\hline
\end{tabular}

Figure 1. Pre-operative hearing thresholds (Pre-op, $n=15$ ), post-operative hearing thresholds at activation day (activation, $n=15)$, at one month after activation $(1 \mathrm{M}, n=15)$ and at three months after activation. $(3 \mathrm{M}, n=14)$. Shaded areas represent the maximal and minimal standard deviations of the pre-operative data (in blue) and of the activation day data (in orange). S.D. = standard deviation .

\subsection{Six-Month Follow-Up Data}

At the $6 \mathrm{M}$ time point $\left(\mathrm{N}_{6 \mathrm{~m}}=13\right)$, all participants had measurable hearing thresholds. Figure 2 describes their hearing thresholds from pre-operative visit to the $6 \mathrm{M}$ time point. Linear mixed-effect analysis showed that changes in hearing thresholds between visits were not all similar with at least one change in the four visits as statistically significantly different from others $(\mathrm{F}(4,408)=26.6, p<0.001)$ and were as well not all similar with at least one change in the five testing frequencies as statistically significantly different from others $(F(6,408)=257.1, p<0.001)$ with a significant interaction effect between frequency and visit $(\mathrm{F}(24,408)=2.3, p=0.001)$. Post hoc pairwise multi-comparisons indicated that changes at activation visit, at $1 \mathrm{M}$, at $3 \mathrm{M}$ and at $6 \mathrm{M}$ time points, were significantly higher from hearing thresholds measured at the preoperative visit between $125 \mathrm{~Hz}$ and $1000 \mathrm{~Hz}$. No significant differences were found at both $2000 \mathrm{~Hz}$ and $4000 \mathrm{~Hz}$ along the follow-up. No significant difference was found between post-operative hearing thresholds.

At $6 \mathrm{M}$ time point $\left(\mathrm{N}_{6 \mathrm{~m}}=13\right)$, five participants $(38.5 \%)$ had complete $\mathrm{HP}$ (range $\left.=(75: 118) \%\right)$, and eight participants $(61.5 \%)$ had partial HP (range $=(27: 61) \%)$. No participant had total loss of hearing or minimal HP according the HEARRING classification.

Average $\mathrm{HL}$ in regards to the preceding time point within the period of activation visit and the $6 \mathrm{M}$ visit was stable (Table 3 ), as there was no significant change across time points ( $t$-tests; $\mathrm{HL}$ at $1 \mathrm{M}$ vs. at $3 \mathrm{M}$ time points $(p=0.16), \mathrm{HL}$ at $1 \mathrm{M}$ vs. $6 \mathrm{M}$ time points $(p=0.33)$ and HL at $3 \mathrm{M}$ vs. $6 \mathrm{M}$ time points $(p=0.18)$ ). Similarly, within the same period, mean HL in the low frequency region $(125-500 \mathrm{~Hz})$ was found to be stable (Table 3 ) with no significant change in mean HL across time points ( $t$-tests; HL at $1 \mathrm{M}$ vs. $3 \mathrm{M}$ time points $(p=0.48)$, HL at $1 \mathrm{M}$ vs. $6 \mathrm{M}$ time points $(p=0.44)$ and $\mathrm{HL}$ at $3 \mathrm{M}$ vs. $6 \mathrm{M}$ time points $(p=0.45))$. Figure 2 illustrates hearing threshold shifts within the low-frequency region $(125-500 \mathrm{~Hz})$ at one time point vs. the preceding time point. At one month after activation visit (Figure 3), ten participants had PTA increases above $+20 \mathrm{~dB}$, and five participants had hearing shifts that were relatively stable between 0 and $20 \mathrm{~dB}$. The latter group consisted of subjects with complete HP as defined by the HEARRING group. All following time points presented equivalent hearing threshold shifts between +20 and $-20 \mathrm{~dB}$, with a general tendency of more subjects within the $(0,-20 \mathrm{~dB})$ range at the $6 \mathrm{M}$ time point. 


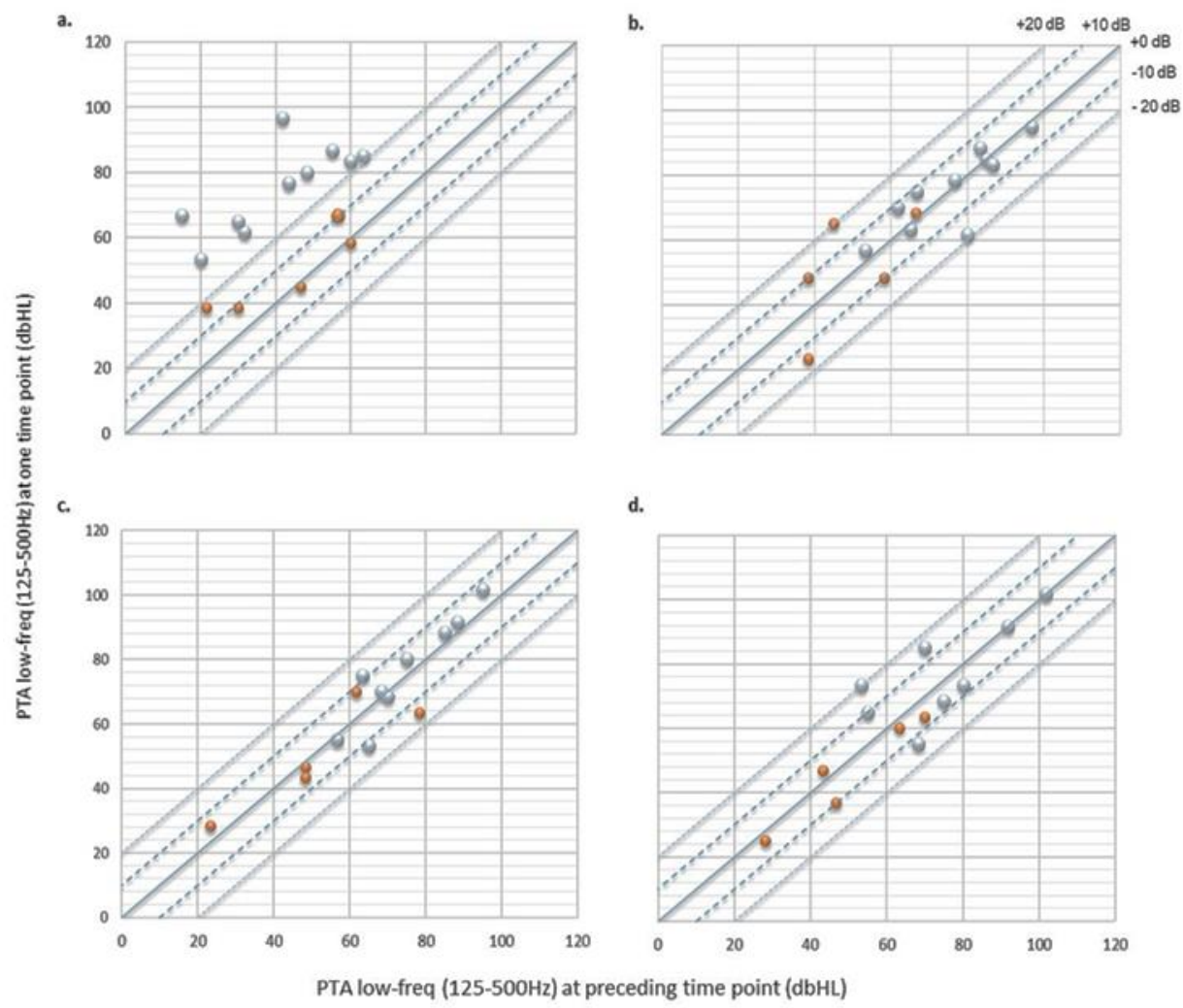

Figure 2. Scatterplots of low-frequency $(125-500 \mathrm{~Hz})$ pure-tone audiometry (PTA) at one time point vs. preceding time point: (a) activation vs. pre-operative thresholds $(n=15) ;(\mathbf{b}) 1 \mathrm{M}$ after activation vs. activation thresholds $(n=15)$; (c) $3 \mathrm{M}$ vs. $1 \mathrm{M}$ after activation thresholds $(n=14)$; (d) $6 \mathrm{M}$ vs. $3 \mathrm{M}$ after activation thresholds $(n=13)$. The solid line indicates no change in PTA, the dashed lines refer to $10 \mathrm{~dB}$ shift in PTA and the dotted lines to $20 \mathrm{~dB}$ shift in PTA. Orange circles indicate participants with complete hearing preservation and grey circles participants with partial hearing preservation as defined in the HEARRING group [18].

Table 3. Average hearing loss over follow-up vs. preceding visit (dB HL) up to 6 months follow-up $(n=13)$ in both full range and low-frequency pure-tone audiometry.

\begin{tabular}{ccccc}
\hline Time Point: & Activation & $\mathbf{1 M}$ & $\mathbf{3 M}$ & $\mathbf{6 M}$ \\
\hline & \multicolumn{1}{c}{ Full range Hearing loss $(25-4000 \mathrm{~Hz})(\mathrm{dB})$} & \\
average & 11 & 0.2 & 1.6 & -0.4 \\
S.D. & 7.8 & 2.9 & 4.7 & 4.2 \\
& Low-Frequency & Hearing loss & $(125-500 \mathrm{~Hz})(\mathrm{dB})$ & \\
average & 25 & 0.9 & 0.4 & -0.1 \\
S.D. & 18.1 & 10.6 & 7.7 & 9.9 \\
\hline
\end{tabular}




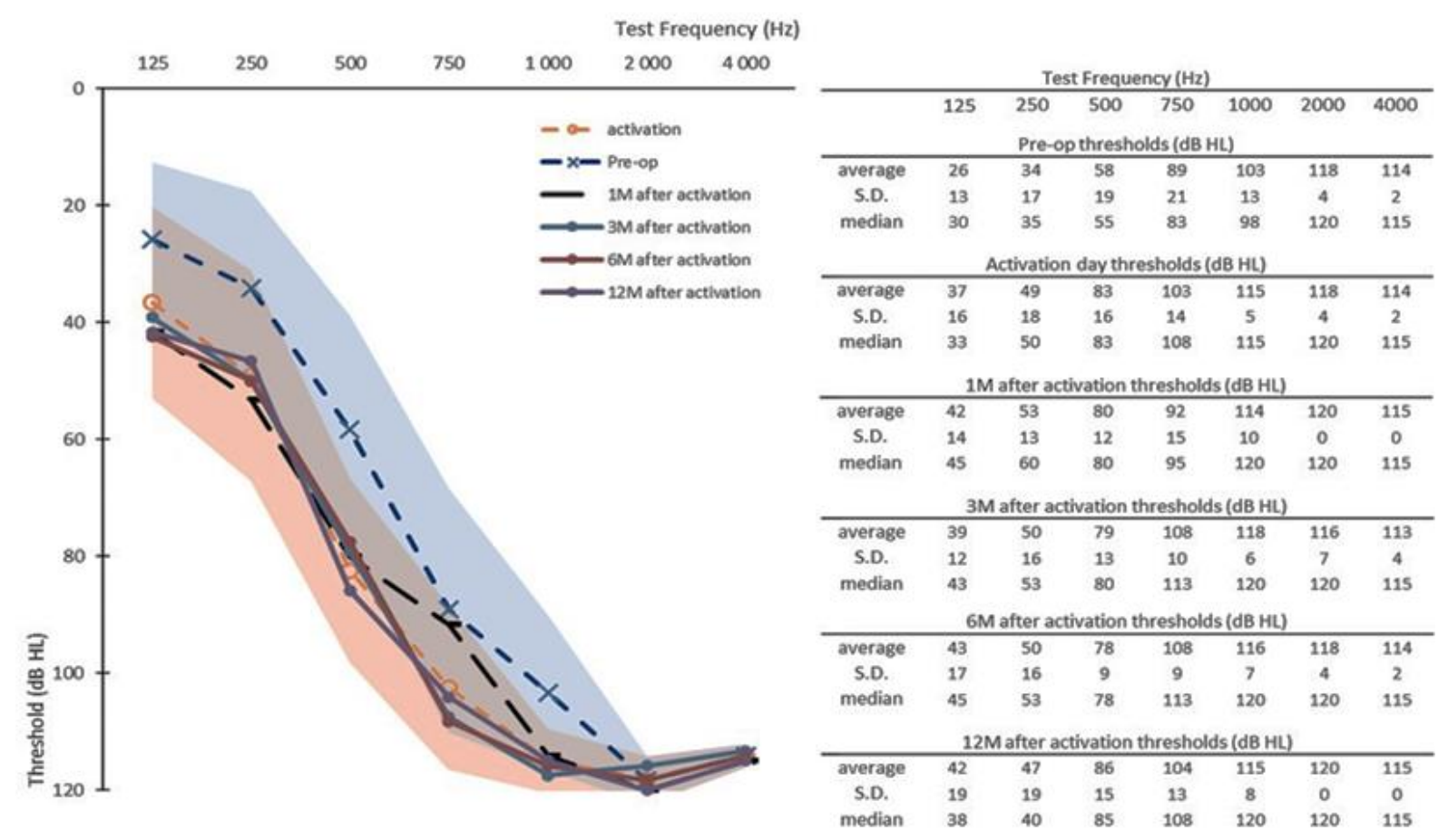

Figure 3. Pre-operative hearing thresholds (Pre-op, $n=6$ ), post-operative hearing thresholds at activation day $(n=6)$, at one month $(1 \mathrm{M})$ after activation $(n=6)$, at three months $(3 \mathrm{M})$ after activation $(n=6)$, at six months $(6 \mathrm{M})$ after activation $(n=6)$ and at 12 months $(12 \mathrm{M})$ after activation $(n=6)$. Shaded areas represent the maximal and minimal standard deviations of the pre-operative data (in blue) and of the activation day data (in orange). S.D. = standard deviation.

\subsection{Twelve-Month Follow-Up Data}

At the $12 \mathrm{M}$ time point $\left(\mathrm{N}_{12 \mathrm{~m}}=6\right)$, all remaining participants had measurable hearing thresholds, as illustrated in Figure 3. Overall, their average HL over 12 months' follow-up in comparison with the preceding time point was relatively stable (Table 3), both in full range PTAs and PTAs of low-frequency $(125-500 \mathrm{~Hz})$. No participant had total loss of hearing or minimal HP according the HEARRING classification, three participants had complete HP $($ range $=(78: 111) \%)$ and three participants had partial HP $($ range $=(42: 55) \%)$.

\subsection{Functional Hearing and Low-Frequency Hearing Preservation}

Figure 4 describes all PTAs of low-frequency $(125-500 \mathrm{~Hz})$ for participants with functional $\mathrm{HP} \leq 80 \mathrm{~dB}(\mathrm{HL})$. At the pre-operative time point, all fifteen participants had functional HP with mean PTA low-frequency $(125-500 \mathrm{~Hz})=42 \mathrm{~dB} \mathrm{HL}(\mathrm{SD} \pm 16$, median $=43$ ). A total of $66.7 \%$ of participants presented functional $\mathrm{HP}$ (mean $=57 \mathrm{~dB} \mathrm{HL}$ $(\mathrm{SD} \pm 13$, median $=60))$ at activation time point $(\mathrm{Nact}=15)$ and $73.3 \%$ participants at the $1 \mathrm{M}$ time point $(\mathrm{N} 1 \mathrm{~m}=15 ;$ mean $=60 \mathrm{~dB} H L(\mathrm{SD} \pm 16$, median $=63))$. Note that one participant (Subject 4, Table 2) had nonfunctional HP at activation but presented functional hearing one month later (Subject 4, PTA low-frequency $(125-500 \mathrm{~Hz})=80 \mathrm{~dB} \mathrm{HL}$ at activation, PTA low-frequency $(125-500 \mathrm{~Hz})=62 \mathrm{~dB} \mathrm{HL}$ at the $1 \mathrm{M}$ time point). Subject 4 had preserved functional HP over the rest of the follow-up. A total of $71.4 \%$ of participants had functional $\mathrm{HP}$ at the $3 \mathrm{M}$ time point $\left(\mathrm{N}_{3 \mathrm{~m}}=14(\right.$ mean $=57 \mathrm{~dB} \mathrm{HL}, \mathrm{SD} \pm 15$, median $\left.=59)\right)$ and $76.9 \%$ participants at the $6 \mathrm{M}$ time point $\left(\mathrm{N}_{6 \mathrm{~m}}=13\right.$ (mean $=57 \mathrm{~dB} H \mathrm{HL}, \mathrm{SD} \pm 16$, median $\left.=62\right)$ ). A total of $83.3 \%$ of participants had low frequency PTAs $\leq 80 \mathrm{~dB}(\mathrm{HL})$ at the $12 \mathrm{M}$ time point $\left(\mathrm{N}_{2 \mathrm{~m}}=6\right.$, mean $=53 \mathrm{~dB} \mathrm{HL}(\mathrm{SD} \pm 9$, median $=52)$. For all subjects with functional hearing, standard HP evaluations showed that at activation $\left(\mathrm{N}_{\mathrm{act}}=10\right)$, around $60 \%$ of subjects had at least partial HP $(0-30 \mathrm{~dB})$ and approximatively $40 \%$ minimal $\mathrm{HP}(>30 \mathrm{~dB})$. At the $1 \mathrm{M}$ time point $\left(\mathrm{N}_{1 \mathrm{~m}}=11\right)$, around $55 \%$ of subjects had at least partial $\mathrm{HP}$ and $45 \%$ minimal HP. At the $3 \mathrm{M}$ time point $\left(\mathrm{N}_{3 \mathrm{~m}}=11\right), 64 \%$ of subjects had at least partial $\mathrm{HP}$ and $36 \%$ minimal HP. At the $6 \mathrm{M}$ time point $\left(\mathrm{N}_{6 \mathrm{~m}}=10\right)$, around $70 \%$ of subjects had at least 
partial HP and $30 \%$ minimal HP. At the $12 \mathrm{M}$ time point $\left(\mathrm{N}_{12 \mathrm{~m}}=5\right)$, around $80 \%$ of subjects had at least partial HP and 20\% minimal HP.

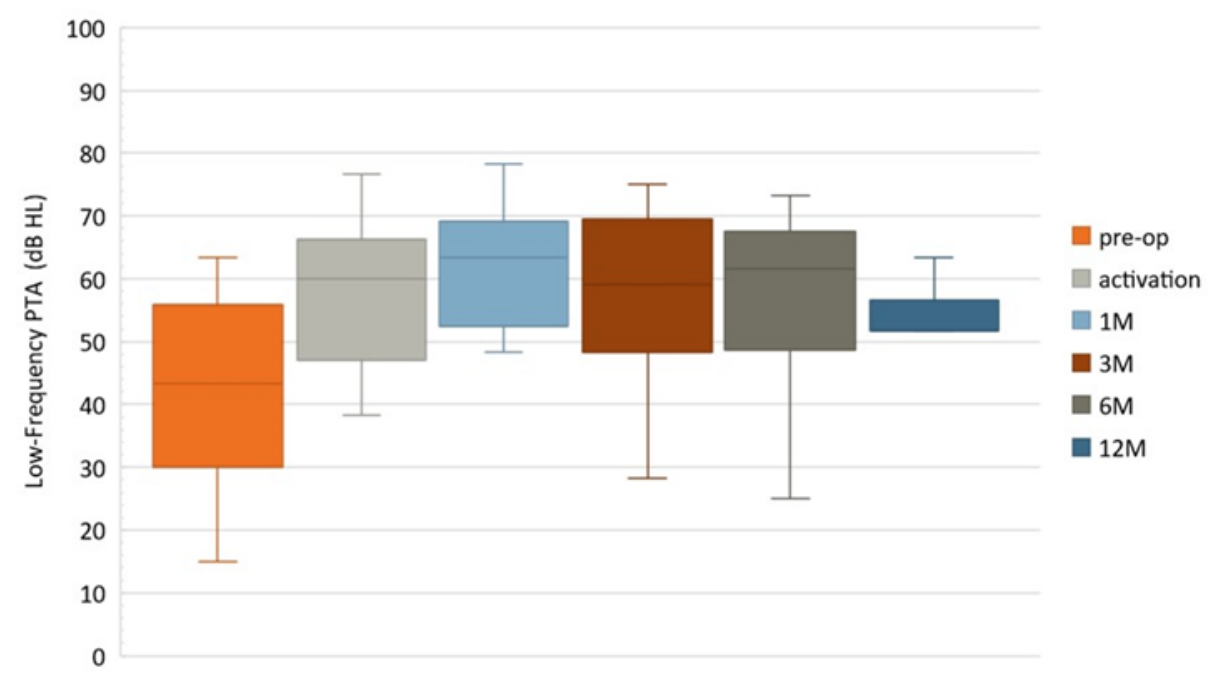

Figure 4. Boxplots of low-frequency $(125-500 \mathrm{~Hz})$ pure tone audiometry for participants with functional hearing $\leq 80 \mathrm{~dB}$ (HL).

\section{Discussion}

To the best of our knowledge, this is the first study that investigated HP in unilateral adult $\mathrm{CI}$ recipients with only the $\mathrm{EVO}^{\mathrm{TM}}$ electrode array up to 12-months follow-up. The $\mathrm{EVO}^{\mathrm{TM}}$ electrode array was originally designed for less traumatic insertions [16] and satisfying HP scores [17]. Combining soft surgery and appropriate electrode arrays, among other recent recommendations like the use of the dexamethasone $[17,22,23]$, are key to increasing HP probability after implantation and on a long term. One key measure being hearing thresholds, it is noteworthy that both low-frequency range and full-frequency range including higher frequencies should both be tested. If the first range usually represents the functional hearing abilities of a subject, the second considers the full spectrum that is necessary in the daily environment and highlights cochlear integrity [24].

\subsection{Hearing Preservation Stability over Follow-Up}

With full range PTAs, none of the study participants had complete loss of hearing or minimal HP at any time point during follow-up with an overall 100\% HP (both partial and complete) detection following the HEARRING group classification. Despite the different number of tested participants, the distribution of HP scores along the different time points was reasonably equivalent. Although the current sample size is quite limited, these data are mostly aligned with the evidence reported in the literature on comparable electrode lengths and CI procedures [25-27].

Complete low-frequency HP was obtained in (33-40\%) range at the early follow-up, in $38.5 \%$ at $6 \mathrm{M}$ and $66.7 \%$ at $12 \mathrm{M}$. Higher rates of complete low-frequency $\mathrm{HP}$ at 1 month $(68 \%)$ have been reported in a retrospective study but with different inclusion criteria (PTA $125-750 \mathrm{~Hz}$ ) and several types of electrode arrays [28]. Another study using a slim mediolar electrode $(n=17)$, reported $41 \%$ of complete low-frequency HP at 43 days (range 3-93) and at 582 days (range 229-1041) after implantation. Using different classification techniques, other studies reported comparable complete HP rates ranging from 25 to $77 \%[9,17,21,29]$.

At activation, the HL shift in this study was $11 \mathrm{~dB}$ for full range PTA and $25 \mathrm{~dB}$ for PTAs of low-frequency $(125-500 \mathrm{~Hz})$. These shifts remained stable up to $6 \mathrm{M}$ after activation with no significant deterioration. This highlights the fact that the major hearing deterioration could occur in the early months after surgery. Interestingly, the subjects who chose to remain with the EAS up to $12 \mathrm{M}$ after activation presented less hearing deterioration with 
lower shifts for both full range PTA (mean: 7.4 dB) and PTAs of low-frequency $(125-500 \mathrm{~Hz}$ ) (mean: $16.7 \mathrm{~dB}$ ). Other studies presented comparable HL values $[19,28,30]$.

It is noteworthy to point to the difference of PTA criteria on inclusion across studies and its impact on establishing HP profiles of similar electrode arrays on a larger scale. Differences in the choice of assessment of full range PTA or low-frequency PTA at inclusion, and which frequency range, constitute a major obstacle to perform meta-analysis and draw a larger picture.

\subsection{Functional Hearing Preservation}

One of the limits of the HEARRING classification is that it does not indicate functional hearing. For instance, Subject 14 had partial HP from activation to the $6 \mathrm{M}$ time point and yet presented no functional hearing with PTAs of low-frequency $(125-500 \mathrm{~Hz}) \geq 80 \mathrm{~dB} \mathrm{HL}$. This could explain why this participant chose not to carry on with the EAS, as we could assume there was no amplification benefit. The main challenge remains on how to define functional hearing. There are several recent recommendations in the literature on choosing one definition over the other: median in low frequency hearing at 250 and $500 \mathrm{~Hz}$ of $70 \mathrm{~dB}$ or better [31], or pure-tone threshold no poorer than $85 \mathrm{~dB} \mathrm{HL}$ at $250 \mathrm{~Hz}$ [24], or PTAs of low-frequency $(125-500 \mathrm{~Hz}) \geq 80 \mathrm{~dB}$ HL [19], among others (e.g., [32]). The definition is rather arbitrary, may change the outcomes of a dataset from one formula to another and complicate literature comparisons. Determining a common formula for functional hearing seems to be crucial, especially given that this variable can be very informative to the success of EAS use and the atraumatic nature of an electrode array. Considering the EAS eligibility criterion for the current study (PTAs of low-frequency $(125-500 \mathrm{~Hz}) \leq 70 \mathrm{~dB}$ at inclusion), the formula used by Iso-Mustajärvi et al. [19] seemed most interesting for the current dataset, as all hearing thresholds $\leq 500 \mathrm{~Hz}$ could be included. A total of $66.7 \%, 73 . \%$, $71.4 \%, 76.9 \%$ and $83.3 \%$ of the participants presented functional hearing at activation at $1 \mathrm{M}$, $3 \mathrm{M}, 6 \mathrm{M}$ and $12 \mathrm{M}$ time points, respectively. Interestingly, the detection of functional hearing increased over time in the different sample sizes who chose not to quit the study and keep the EAS. Iso-Mustajärvi et al. [19] report that $83 \%$ of tested ears with a slim mediolar electrode had functional hearing at activation and $82 \%$ at latest follow-up (mean 582 days). Considering the reported wide range of the activation day (range 3-93) and of their followup time point (range 229-1041), the current data are comparable with theirs. On a larger sample size, Helbig et al. [9] found that functional low-frequency residual hearing (PTAs low-frequency $(125-500 \mathrm{~Hz})<80.0 \mathrm{~dB} \mathrm{HL})$ was $85.3 \%$ postoperatively, $87.9 \%$ after the $12 \mathrm{M}$ time point and $95.0 \%$ for longer follow-up. Lee et al. [25] assessed HP on 34 ears and found that $41 \%$ had functional hearing (no poorer than $85 \mathrm{~dB} \mathrm{HL}$ at $250 \mathrm{~Hz}$ ), while $59 \%$ did not at one-year post-activation. Looking to the current dataset at $12 \mathrm{M}$, all six participants had better hearing thresholds than $85 \mathrm{~dB} \mathrm{HL}$ at $250 \mathrm{~Hz}$. Moran et al. [31] reported that $39.5 \%$ of 86 tested participants presented functional hearing as median hearing at 250 and $500 \mathrm{~Hz}$ of $70 \mathrm{~dB}$ or better at 3 months postoperatively. Using the same method, Harrison et al. [26] found $32.7 \%$ of their participants with functional hearing postoperatively. In the current dataset, $35.7 \%$ of the participants presented functional hearing using the above definition at $3 \mathrm{M}$. In sum, the current study presents comparable evidence to the literature when comparing different methods of functional preservation.

All subjects with functional hearing presented at least partial HP or minimal HP and no case of loss of residual hearing. Although the sample size is comparatively smaller in the current study, these outcomes are relatively aligned with recent studies reporting on hearing preservation and using the same method $[9,21,28,30]$.

\subsection{Correlation with Age}

When investigating correlations between potential predictive factors on hearing outcomes, only one significant correlation was found between age at inclusion and PTAs of low-frequency $(125-500 \mathrm{~Hz})$ at activation $(\mathrm{r}=0.56 ; p=0.03)$. Iso-Mustajärvi et al. [19] also found a moderate correlation between age and residual hearing but at the end of 
the follow-up. However, the predictive impact of age on hearing preservation remains uncertain, as several studies have shown better outcomes on residual hearing [20,33], while other studies did not report any significant impact $[26,34,35]$. Although the literature reported other predictive factors such as duration of hearing loss [36,37], they were not highlighted in the current dataset, possibly due the limited number of participants.

\subsection{EAS Adherence}

In the current study, subjects could quit the protocol at any time of the follow-up and were giving the choice between keeping the EAS or being fitted with an ES starting from $6 \mathrm{M}$. At all the time points, all participants were eligible for EAS (i.e., eligibility criterion being at least one detectable hearing threshold). At the $6 \mathrm{M}$ time point, $92.9 \%(13 / 14)$ of participants decided to keep the EAS when given the choice, out of which $46.2 \% \mathrm{kept}$ it at 12M. Spitzer et al. [38] reported EAS eligibility (postoperative thresholds $\leq 75 \mathrm{~dB}$ HL for both 125 and $250 \mathrm{~Hz}$ ) in 64.5\% (49/76) at activation, 55.7\% (44/79) at 3 months postoperatively and 51\% (24/47) at 12 months postoperatively. At each time point, the authors reported that approximately half of the participants chose to use EAS with approx. $20 \%$ at 12 months postoperatively. A total of $78 \%$ of CI ears in Iso-Mustajärvi et al. were EAS eligible, of which $72 \%$ were fitted with an EAS and only $44 \%$ chose to keep the EAS. Harrison et al. [26] reported that only 2 of 17 eligible subjects chose to use EAS. Out of 32 EAS users in the study by Roland et al. [32], 84\% were still using the EAS after 12-month follow-up and $72 \%$ after 5 years. Mamelle et al. [28] reported that 20/44 of their participants stopped using EAS, 6 of which were because of aesthetic issues, 8 of which were because of acoustic discomfort and 6 of which were because of total HL. Regardless of the several EAS eligibility criteria, the concept of adherence to EAS use has been briefly discussed in the literature, and limited evidence has been reported on EAS users' reasons to drop. In the current study, two reasons mostly underlined the choice of our participants in quitting the study. The first one, and in most cases, was personal constraints. The second one was hoping for a better benefit with ES use whether because of their belief that no benefit is coming from EAS or because they believe the benefit will be better with ES. Spitzer et al. [38] investigated the reasons behind the rejection of EAS use. A total of $29 \%$ of rejections was because of hearing issues ( $21 \%$ borderline thresholds; $8 \%$ of fluctuating hearing), and $46 \%$ were because of discomfort or equipment preference. Regardless of the EAS brand or the electrode type, these figures highlight the urgent need to focus on whether to improve equipment or EAS criteria to benefit more EAS eligible candidates. Interestingly, the current study did not define strict EAS criteria after activation, yet a comparable number of EAS adherents was found with several studies with stricter criteria.

\section{Conclusions}

The EVO ${ }^{\mathrm{TM}}$ electrode array is designed for hearing preservation surgeries, and the present data show that all participants had measurable hearing levels with complete and partial preservation profiles. Thresholds remained stable over the follow-up period, with a steady hearing threshold shift suggesting that hearing loss was stable along the follow-up period. Participants who chose to remain with EAS had better hearing preservation profiles and lower hearing threshold shift. This study confirms the atraumatic profile of the EVO ${ }^{\mathrm{TM}}$ electrode array, but other studies on larger populations should be performed.

Supplementary Materials: The following are available online at https:/ / www.mdpi.com/article/ $10.3390 /$ jcm10235604/s1. Table S1. Hearing preservation scores and classification according to the HEARING group classification [18] over the 12 months' follow-up at full range hearing loss $(125-4000 \mathrm{~Hz})$ and low-frequency PTA $(125-500 \mathrm{~Hz})$.

Author Contributions: Conceptualization, methodology, validation, all authors; formal analysis, C.K. and M.H.; investigation, N.G., C.P.-W., B.G., V.F.-V., E.T., C.V., I.M. and Y.N. resources, M.A.; data curation, M.A. and C.K.; writing—original draft preparation, C.K.; writing—review and editing, C.K., 
M.H., D.G., N.G. and Y.N visualization, C.K.; supervision, M.H.; project administration, D.G.; funding acquisition, D.G. All authors have read and agreed to the published version of the manuscript.

Funding: This work was funded by Oticon Medical.

Institutional Review Board Statement: This study was carried out in accordance with the regulations in force based on the provisions stipulated in the Declaration of Helsinki and was registered in the U.S. National Library of Medicine ClinicalTrials.gov database (identifier NCT02966379). For this purpose, the favourable opinion of the CPP was required and obtained (RCB:2015-A00445-44), as well as the authorization of the French health authorities (ANSM). Clinical research was carried out in accordance with good clinical practices (ICH standard) and NF ISO 14155:2011 and in accordance with the MR001 reference methodology of the French National Information Science and Liberties Commission (CNIL).

Informed Consent Statement: Informed consent was obtained from all subjects involved in the study.

Data Availability Statement: All data generated or analysed during this study are included in this article and its Supplementary material files. Further enquiries can be directed to the corresponding author.

Acknowledgments: The authors would like to thank the participants for their involvement in the study and all the staff of participating CI centres and of Oticon Medical for helping in data collection and follow-up.

Conflicts of Interest: Oticon Medical covered the trial costs but did not provide honoraria to the investigators and staff of the participating CI centres. M. Hoen, C. Karoui, M. Ardoint and D. Gnansia are employees of Oticon Medical. The authors have no other relevant affiliations or financial involvement with any organization or entity with a financial interest in or financial conflict with the subject matter or materials discussed in the manuscript apart from those disclosed.

\section{References}

1. Gantz, B.J.; Turner, C.W. Combining acoustic and electrical hearing. Laryngoscope 2010, 113, 1726-1730. [CrossRef] [PubMed]

2. James, C.J.; Fraysse, B.; Deguine, O.; Lenarz, T.; Mawman, D.; Ramos, Á.; Ramsden, R.; Sterkers, O. Combined Electroacoustic Stimulation in Conventional Candidates for Cochlear Implantation. Audiol. Neurotol. 2006, 11, 57-62. [CrossRef]

3. Mom, T.; Bachy, A.; Houette, A.; Pavier, Y.; Pastourel, R.; Gabrillargues, J.; Saroul, N.; Gilain, L.; Avan, P. Cochlear implantation through the round window with a straight slotted electrode array: Optimizing the surgical procedure. Eur. Arch. Oto-RhinoLaryngol. 2015, 273, 853-858. [CrossRef]

4. Lehnhardt, E. Intrakochleäre Plazierung der Cochlear-Implant-Elektroden in soft surgery technique [Intracochlear placement of cochlear implant electrodes in soft surgery technique]. HNO 1993, 41, 356-359. (In German) [PubMed]

5. Sierra, C.; Calderón, M.; Bárcena, E.; Tisaire, A.; Raboso, E. Preservation of Residual Hearing After Cochlear Implant Surgery with Deep Insertion Electrode Arrays. Otol. Neurotol. 2019, 40, e373-e380. [CrossRef]

6. Hodges, A.V.; Schloffman, J.; Balkany, T. Conservation of residual hearing with cochlear implantation. Am. J. Otol. 1997, 18, 179-183.

7. Gantz, B.J.; Turner, C.; Gfeller, K.E.; Lowder, M.W. Preservation of Hearing in Cochlear Implant Surgery: Advantages of Combined Electrical and Acoustical Speech Processing. Laryngoscope 2005, 115, 796-802. [CrossRef]

8. Mertens, G.; Punte, A.K.; Cochet, E.; De Bodt, M.; Van de Heyning, P. Long-term Follow-up of Hearing Preservation in Electric-Acoustic Stimulation Patients. Otol. Neurotol. 2014, 35, 1765-1772. [CrossRef]

9. Helbig, S.; Adel, Y.; Rader, T.; Stöver, T.; Baumann, U. Long-term Hearing Preservation Outcomes After Cochlear Implantation for Electric-Acoustic Stimulation. Otol. Neurotol. 2016, 37, e353-e359. [CrossRef] [PubMed]

10. Bourn, S.; Goldstein, M.R.; Jacob, A. Hearing Preservation in Elderly Cochlear Implant Recipients. Otol. Neurotol. 2020, 41, 618-624. [CrossRef] [PubMed]

11. Fitzgerald, M.B.; Sagi, E.; Jackson, M.; Shapiro, W.H.; Roland, J.J.T.; Waltzman, S.; Svirsky, M. Reimplantation of Hybrid Cochlear Implant Users with a Full-Length Electrode After Loss of Residual Hearing. Otol. Neurotol. 2008, 29, 168-173. [CrossRef] [PubMed]

12. Adunka, O.; Unkelbach, M.H.; Mack, M.G.; Radeloff, A.; Gstoettner, W. Predicting Basal Cochlear Length for Electric-Acoustic Stimulation. Arch. Otolaryngol. Head Neck Surg. 2005, 131, 488-492. [CrossRef] [PubMed]

13. Gstoettner, W.K.; Helbig, S.; Maier, N.; Kiefer, J.; Radeloff, A.; Adunka, O.F. Ipsilateral Electric Acoustic Stimulation of the Auditory System: Results of Long-Term Hearing Preservation. Audiol. Neurotol. 2006, 11, 49-56. [CrossRef]

14. Gstoettner, W.; Helbig, S.; Settevendemie, C.; Baumann, U.; Wagenblast, J.; Arnoldner, C. A new electrode for residual hearing preservation in cochlear implantation: First clinical results. Acta Oto-Laryngol. 2009, 129, 372-379. [CrossRef] [PubMed] 
15. Sipari, S.; Iso-Mustajärvi, M.; Matikka, H.; Tervaniemi, J.; Koistinen, A.; Aarnisalo, A.; Sinkkonen, S.T.; Löppönen, H.; Dietz, A. Cochlear Implantation with a Novel Long Straight Electrode: The Insertion Results Evaluated by Imaging and Histology in Human Temporal Bones. Otol. Neurotol. 2018, 39, e784-e793. [CrossRef]

16. Nguyen, Y.; Miroir, M.; Kazmitcheff, G.; Sutter, J.; Bensidhoum, M.; Ferrary, E.; Sterkers, O.; Grayeli, A.B. Cochlear Implant Insertion Forces in Microdissected Human Cochlea to Evaluate a Prototype Array. Audiol. Neurotol. 2012, 17, 290-298. [CrossRef] [PubMed]

17. Bento, R.F.; Danieli, F.; Magalhães, A.T.D.M.; Gnansia, D.; Hoen, M. Residual Hearing Preservation with the Evo®Cochlear Implant Electrode Array: Preliminary Results. Int. Arch. Otorhinolaryngol. 2016, 20, 353-358. [CrossRef]

18. Skarzynski, H.; Van de Heyning, P.; Agrawal, S.; Arauz, S.L.; Atlas, M.; Baumgartner, W.; Caversaccio, M.; DE Bodt, M.; Gavilan, J.; Godey, B.; et al. Towards a consensus on a hearing preservation classification system. Acta Oto-Laryngol. 2013, 133, 3-13. [CrossRef]

19. Iso-Mustajärvi, M.; Sipari, S.; Löppönen, H.; Dietz, A. Preservation of residual hearing after cochlear implant surgery with slim modiolar electrode. Eur. Arch. Oto-Rhino-Laryngol. 2019, 277, 367-375. [CrossRef] [PubMed]

20. Haber, K.; Neagu, A.; Konopka, W.; Amernik, K.; Gheorghe, D.C.; Drela, M.; Wrukowska-Niemczewska, I.; Mierzwiński, J. The influence of Slim Modiolar electrode on residual hearing in pediatric patients. Eur. Arch. Oto-Rhino-Laryngol. 2020, 278, $2723-2732$. [CrossRef]

21. Nguyen, Y.; Mosnier, I.; Borel, S.; Ambert-Dahan, E.; Bouccara, D.; Bozorg-Grayeli, A.; Ferrary, E.; Sterkers, O. Evolution of electrode array diameter for hearing preservation in cochlear implantation. Acta Oto-Laryngol. 2012, 133, 116-122. [CrossRef]

22. James, C.; Albegger, K.; Battmer, R.; Burdo, S.; Deggouj, N.; Deguine, O.; Dillier, N.; Gersdorff, M.; Laszig, R.; Lenarz, T.; et al. Preservation of residual hearing with cochlear implantation: How and why. Acta Oto-Laryngol. 2005, 125, 481-491. [CrossRef]

23. Nguyen, Y.; Bernardeschi, D.; Kazmitcheff, G.; Miroir, M.; Vauchel, T.; Ferrary, E.; Sterkers, O. Effect of Embedded Dexamethasone in Cochlear Implant Array on Insertion Forces in an Artificial Model of Scala Tympani. Otol. Neurotol. 2015, 36, 354-358. [CrossRef]

24. Derinsu, U.; Serin, G.M.; Akdaş, F.; Batman, Ç. Cochlear Implantation: Is hearing preservation necessary in severe to profound hearing loss? J. Craniofacial Surg. 2011, 22, 520-522. [CrossRef] [PubMed]

25. Lee, G.; Lee, S.; Chung, J.-H.; Choi, J.W. Preimplant Hearing Threshold: An Important Predictor of Hearing Preservation in Cochlear Implantation with Lateral Wall Electrodes. Otol. Neurotol. 2020, 42, e145-e152. [CrossRef]

26. Harrison, L.; Manjaly, J.G.; Ellis, W.; Lavy, J.A.; Shaida, A.; Khalil, S.S.; Saeed, S.R. Hearing Preservation Outcomes with Standard Length Electrodes in Adult Cochlear Implantation and the Uptake of Electroacoustic Stimulation. Otol. Neurotol. 2020, 41, 1060-1065. [CrossRef]

27. Schart-Morén, N.; Erixon, E.; Li, H.; Rask-Andersen, H. Cochlear implantation and residual hearing preservation long-term follow-up of the first consecutively operated patients using the round window approach in Uppsala, Sweden. Cochlea- Implant. Int. 2020, 21, 246-259. [CrossRef]

28. Mamelle, E.; Granger, B.; Sterkers, O.; Lahlou, G.; Ferrary, E.; Nguyen, Y.; Mosnier, I. Long-term residual hearing in cochlear implanted adult patients who were candidates for electro-acoustic stimulation. Eur. Arch. Oto-Rhino-Laryngol. 2019, 277, 705-713. [CrossRef] [PubMed]

29. Helbig, S.; Baumann, U.; Hey, C.; Helbig, M. Hearing Preservation After Complete Cochlear Coverage in Cochlear Implantation with the Free-Fitting FLEXSOFT Electrode Carrier. Otol. Neurotol. 2011, 32, 973-979. [CrossRef] [PubMed]

30. Lenarz, T.; Buechner, A.; Lesinski-Schiedat, A.; Timm, M.; Salcher, R. Hearing Preservation with a New Atraumatic Lateral Wall Electrode. Otol. Neurotol. 2020, 41, e993-e1003. [CrossRef] [PubMed]

31. Moran, M.; Dowell, R.C.; Iseli, C.; Briggs, R.J.S. Hearing Preservation Outcomes for 139 Cochlear Implant Recipients Using a Thin Straight Electrode Array. Otol. Neurotol. 2017, 38, 678-684. [CrossRef] [PubMed]

32. Jr, J.T.R.; Gantz, B.J.; Waltzman, S.B.; Parkinson, A.J. Long-term outcomes of cochlear implantation in patients with high-frequency hearing loss. Laryngoscope 2017, 128, 1939-1945. [CrossRef]

33. Lenarz, T.; James, C.; Cuda, D.; O’Connor, A.F.; Frachet, B.; Frijns, J.H.; Klenzner, T.; Laszig, R.; Manrique, M.; Marx, M.; et al. European multi-centre study of the Nucleus Hybrid L24 cochlear implant. Int. J. Audiol. 2013, 52, 838-848. [CrossRef]

34. Friedmann, D.; Peng, R.; Fang, Y.; McMenomey, S.O.; Roland, J.J.T.; Waltzman, S.B. Effects of loss of residual hearing on speech performance with the CI422 and the Hybrid-L electrode. Cochlea- Implant. Int. 2015, 16, 277-284. [CrossRef]

35. Zanetti, D.; Nassif, N.; DE Zinis, L.O.R. Fattori influenzanti la conservazione dei residui uditivi negli impianti cocleari. Acta Otorhinolaryngol. Ital. 2015, 35, 433-441. [CrossRef] [PubMed]

36. Causon, A.; Verschuur, C.; Newman, T.A. A Retrospective Analysis of the Contribution of Reported Factors in Cochlear Implantation on Hearing Preservation Outcomes. Otol. Neurotol. 2015, 36, 1137-1145. [CrossRef]

37. Wanna, G.B.; O'Connell, B.P.; Francis, D.O.; Gifford, R.; Hunter, J.; Holder, J.; Bennett, M.; Rivas, A.; Labadie, R.F.; Haynes, D.S. Predictive factors for short- and long-term hearing preservation in cochlear implantation with conventional-length electrodes. Laryngoscope 2017, 128, 482-489. [CrossRef]

38. Spitzer, E.R.; Waltzman, S.; Landsberger, D.M.; Friedmann, D. Acceptance and Benefits of Electro-Acoustic Stimulation for Conventional-Length Electrode Arrays. Audiol. Neurotol. 2020, 26, 17-26. [CrossRef] [PubMed] 